Quantitative modelling of the erosive removal of a thin soil deposit by impinging liquid jets

Oevermann, D.*, Bhagat, R.K, Fernandes, R.R. and Wilson, D.I.

Department of Chemical Engineering and Biotechnology, Philippa Fawcett Drive, Cambridge, 5 CB3 0AS, UK

*TU Dresden, Faculty of Mechanical Engineering, Institute of Processing Machines and Mobile Machines, Bergstraße 120, 01062 Dresden, Germany

\author{
Revised Manuscript \\ Wear WEA_2018_1043
}

December 2018

15

Corresponding author

D. Ian Wilson

Department of Chemical Engineering and Biotechnology

Philippa Fawcett Drive

20

Cambridge

CB3 0AS

UK

$\begin{array}{lll} & \text { Tel } & +441223334791 \\ 25 & \text { E-mail } & \text { diw11@cam.ac.uk }\end{array}$




\section{Quantitative modelling of the erosive removal of a thin soil deposit by impinging liquid jets}

Oevermann, D.*, Bhagat, R.K, Rosario Fernandes, R. and Wilson, D.I.

Department of Chemical Engineering and Biotechnology, Philippa Fawcett Drive, Cambridge, CB3 OAS, UK

*TU Dresden, Faculty of Mechanical Engineering, Institute of Processing Machines and Mobile Machines, Bergstraße 120, 01062 Dresden, Germany

\section{Abstract}

Kaye et al. (1995, Wear, 186-187, 413-420) conducted an experimental investigation of the cleaning of thin soil layers by water jets generated from stationary nozzles of diameter 0.25-2 $\mathrm{mm}$ and velocities ranging from $6-40 \mathrm{~m} \mathrm{~s}^{-1}$. The soil layers were prepared by drying a commercial cleaning suspension on polymethylmethacrylate plates. Several of their data sets have been re-analysed and are shown to fit the 'strong soil' model for cleaning by peeling reported by Bhagat et al. (2017, Food Bioproduct Proc., 102, 31-54). The model is demonstrated to be able to explain the trends in cleaning efficiency observed by Kaye $e t$ al. quantitatively, including the transition in efficiency observed at longer times. Kaye et al. also investigated the case of cleaning by a moving nozzle for one set of jet conditions, and reported an increase in cleared area with nozzle velocity. This behaviour is not predicted for the "strong soil' and the model was modified to incorporate a contribution from the milling action of the jet in its impingent zone. This 'very strong soil' result gave good agreement with the data for the area cleared and the shape of the cleared region.

Keywords Cleaning, erosion, liquid jet, model, soil 


\section{Nomenclature}

50 Roman

$a$

$a_{i}$

$a_{i}{ }^{*}$

$a_{x}$

$55 A$

$c_{1}$

$c_{2}$

$c_{3}$

$d_{\mathrm{N}}$

$60 \quad E$

$E_{\mathrm{U}}$

k'

$L$

$\dot{m}$

$65 \quad M$

$p$

$p^{*}$

$Q$

$r$

$70 \quad r$

$r_{\mathrm{o}}$

Re

$t$

$t_{i}$

75

$U_{\mathrm{o}}$

V

$W e_{\mathrm{G}}$

$W e_{\mathrm{L}}$
Radius of cleaned area, [m]

Radius when cleaning front is first seen, [m]

Dimensionless radius when cleaning front is first seen, [-]

Distance to cleaning front on jet path, [m]

Area of the cleared region, $\left[\mathrm{m}^{2}\right]$

Lumped parameters, $c_{1}=\frac{10 \mu U_{\mathrm{o}} \pi^{2}}{3 \rho Q^{2}},\left[\mathrm{~m}^{-3}\right]$

Parameter, Eq. [8], [-]

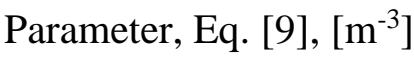

Nozzle diameter, [m]

Efficiency factor, $\left[\mathrm{m}^{-1}\right]$

Prefactor efficiency, $\left[\mathrm{m}^{-1}\right]$

Lumped cleaning rate constant, $\left[\mathrm{m} \mathrm{s} \mathrm{kg}^{-1}\right]$

Distance from nozzle to target, [m]

Mass flow rate, $\left[\mathrm{kg} \mathrm{s}^{-1}\right]$

Momentum flow per unit width, $\left[\mathrm{kg} \mathrm{s}^{-2}\right]$

Radial distance to cleaning front, [m]

Dimensionless radial distance to cleaning front, [-]

Flow rate leaving nozzle, $\left[\mathrm{m}^{3} \mathrm{~s}^{-1}\right]$

Radial co-ordinate, $[\mathrm{m}]$

Boundary layer radius, [m]

Jet radius, $r_{\mathrm{o}}=\frac{1}{2} d_{\mathrm{N}}[\mathrm{m}]$

Reynolds number, defined $R e=\rho U_{o} d_{N} / \mu$

Time, [s]

Induction time, $[\mathrm{s}]$

Jet velocity, $\left[\mathrm{m} \mathrm{s}^{-1}\right]$

Jet's traversal velocity, $\left[\mathrm{m} \mathrm{s}^{-1}\right]$

Weber number gaseous, defined $W e=\rho_{\mathrm{G}} U_{\mathrm{o}}{ }^{2} d_{\mathrm{N}} / \gamma$

Weber number liquid, defined $W e=\rho_{\mathrm{L}} U_{\mathrm{o}}^{2} d_{\mathrm{N}} / \gamma$ 


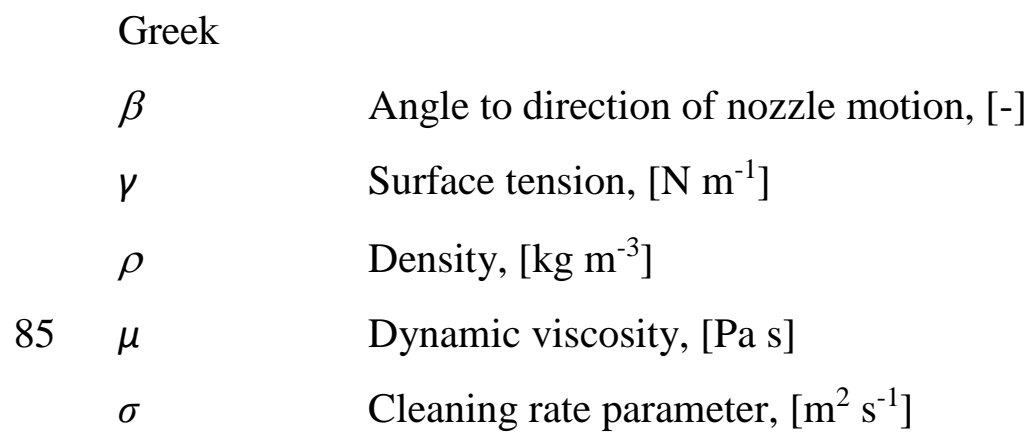

Acronyms

PMMA Polymethylmethacrylate

90 RFZ Radial flow zone 


\section{Introduction}

95 Cleaning, namely the removal of unwanted layers from surfaces, is an example of deliberate and controlled wear. The aim is to remove the soiling layer rapidly without damaging the vessel or device surface. Cleaning is a critically important operation in the food, pharmaceutical and chemical industries where coatings of fouling layers or residual soil layers are generated on a surface from the materials being processed. Many modern manufacturing systems subject to

100 rapid soil formation employ cleaning-in-place systems to remove the soil layer automatically. The methods used depend on the soil to be removed, the surface involved, the nature of the unit and the resources available [1].

Cleaning directly affects manufacturing sustainability as the operation usually consumes water, time, chemicals and energy, simultaneously generating waste products that need to be treated

105 and/or disposed of. The design and operation of cleaning systems has often been based on empirical studies: the need to optimise these resources to improve sustainability requires physically based quantitative models which can be used to predict the rate of cleaning.

Impinging liquid jets, generated by static or rotating spray balls and moving nozzles, are frequently used to clean the internals of storage tanks and vessels as well as individual parts

110 (e.g. in a jet washer). When a liquid jet impinges on a solid surface, it flows radially away from the point of impingement in a thin, fast moving film that exerts a high shear stress on the surface within the radial flow zone (RFZ) bounded by the hydraulic jump (if one exists). This shear stress promotes erosion [2]. The rate of flow of momentum in the radial direction is also appreciable, which can promote peeling. Briscoe et al. [3] termed this process hydrodynamic

115 flow induced erosion and discussed the experimental study of Kaye [4] as involving the initial penetration of the layer under the jet footprint, followed by removal by the lateral fluid flow. The behaviour observed is determined by the nature of the layer.

The penetration of soil layers by liquid jets has been investigated numerically [5,6] and experimentally [7-10]. Mechanisms such as water hammer [6] and compression waves [11]

120 play a role when the jet velocity is high enough to cause compression effects. Detailed models of penetration coupling liquid flow and layer erosion in the region beneath the jet footprint are not in widespread use: jet erosion testing results tend to be interpreted in terms of lumped parameters (e.g. [12]). 
Mathematical models describing the removal of stubborn soils by impinging liquid jets in the RFZ have been developed. Yeckel and Middleman [2] considered the case where the film generated by the jet eroded a viscous (liquid) soil, coupling the shear stress imposed by the jet to the soil motion. Wilson et al. [13] presented a model for the case where the soil is removed by a peeling mechanism, which is controlled by the rate at which the layer undergoes adhesive failure at the soil-substrate interface. These models have become available through new 130 understanding of the hydrodynamics of the thin, fast moving liquid layer created when a jet impinges on a surface $[14,15]$. Other modes of removal exist, often depending on the nature of the jet when it impinges: Meng et al. [16] considered removal by a spray rather than a coherent or near-coherent jet considered here.

Kaye et al. [9] conducted a careful experimental investigation of the cleaning of a dried-on 135 particulate soil from polymethylmethacrylate (PMMA) plates by high speed (up to $40 \mathrm{~m} \mathrm{~s}^{-1}$ ) water jets. This paper describes the application of one of the models introduced by Bhagat et al. [17] to describe the results presented by Kaye et al. and thereby demonstrate how such studies can be used to optimise the rate of cleaning of a troublesome soil.

Kaye et al. studied layers of thickness $0.175 \pm 0.010 \mathrm{~mm}$ created by spin-coating a commercial 140 formulated cleaning product (comprising a suspension of fine particles) on to PMMA surfaces followed by drying in an oven. They observed that the jet took a short time, which they labelled the induction time, $t_{\mathrm{i}}$, to break through the layer at the point of impact. This was followed by the growth of a roughly circular region of clean substrate. Figure 1 presents a sequence of stills from one of their videos. The initial radius, $a_{\mathrm{i}}$, was somewhat larger than the jet radius, $r_{\mathrm{o}}$ : in

145 Figure 1(a), $a_{\mathrm{i}}=0.97 \mathrm{~mm} c f . r_{\mathrm{o}}=0.5 \mathrm{~mm}$. Throughout this paper the jet diameter is assumed to be the same as the nozzle, $d_{\mathrm{N}}$, i.e. $r_{\mathrm{O}}=\frac{1}{2} d_{\mathrm{N}}$.

They presented one figure showing that the area of the cleaned region increased linearly with the square root of time, but they did not explain the evolution in terms of physical principles. They modelled their data using response surface, which is in general suitable for interpolation 150 of results but not for application to other systems. They also presented results for the area cleaned by a moving nozzle: in these experiments a coated disc was rotated and exposed to a jet for a fraction of a revolution.

In this work several of the Kaye et al. video records and a number of their data sets, which Dr Kaye provided for analysis, are compared with the quantitative cleaning model for a 'strong 
155 soil' presented in [17]. Good agreement is obtained for the static nozzle data, and their model for cleaning by a moving nozzle, suitably modified, is shown to explain several features of Kaye et al.'s experimental data. This represents an advance in the capability to use static cleaning tests to predict the performance of moving jets.

\section{Mathematical model}

Peeling occurs when the force applied to a soil layer is strong enough to overcome the adhesive interaction between the layer and the substrate, such that it detaches. The force may not be strong enough to cause breakdown of the layer, i.e. overcome the cohesive interactions within the layer. The initial penetration of the liquid toward the substrate, which Kaye et al. also studied, involves breakdown of the cohesive interactions within the layer and is not considered here. We consider the case where liquid has created an initial cleared region, taken to be circular with radius $a_{\mathrm{i}}$.

Wilson et al. [13] postulated that peeling was directly proportional to the rate of flow of radial momentum per unit width, $M$, via:

$$
\frac{d a}{d t}=k^{\prime} M
$$

170 Here, $t$ is time and $a$ is the location of the peeling front, which in the Kaye et al. experiments is the radius of the circular cleaned region. Parameter $k^{\prime}$ is a cleaning rate constant, which is expected to depend on the magnitude of the substrate-soil interactions and the soil layer thickness. The momentum flux is determined by the radial position: as the liquid flows away from the point of impingement, a boundary layer of slower moving fluid develops at the wall and eventually reaches the free surface $\left(\right.$ see $\left.^{14}\right)$. At some radial location the flow in the film will become turbulent: none of the cases considered here involved a turbulent film.

Bhagat et al. [17] identified two cleaning behaviours differentiated by whether the growing viscous boundary layer in the liquid film had reached the free surface. Substituting an approximate result for $M$ into equation [1] ${ }^{18,14}$ yields the following result which encompasses the change in film behaviour: 


$$
\frac{d a}{d t}=k^{\prime} \frac{3}{5 \pi} \frac{\dot{m} U_{\mathrm{o}}}{a} \frac{1}{\left(1+c_{1}\left(a^{3}-r_{o}^{3}\right)\right)}
$$

Here $\dot{m}$ is the mass flow rate of liquid in the jet, $r_{\mathrm{o}}$ is the jet radius, $U_{\mathrm{o}}$ is the mean velocity in the jet, and $c_{1}$ is a group of parameters and constants. Equation [2] indicates that there are two limiting regimes, namely at $a \sim r_{\mathrm{o}}$ and at large $a$.

(i) Early stage or 'strong soil', $a \sim r_{\mathrm{o}}$

185 In the first case, termed the 'strong soil', $a$ is small so that cleaning occurs within the region where the boundary layer is growing. $M$ is then approximately given by

$$
M=\frac{3 \dot{m}}{5 \pi} \frac{U_{\mathrm{o}}}{r}
$$

where $r$ is the radial co-ordinate. Using [3] to calculate $M$ at the cleaning front yields

$$
\frac{d a}{d t}=\frac{3 k^{\prime} \dot{m}}{5 \pi} \frac{U_{\mathrm{o}}}{a}
$$

Integrating [4] from the point where breakthrough occurs, at location $a_{\mathrm{i}}$ (of order $r_{\mathrm{o}}$ ) and time $t_{\mathrm{i}}$, yields

$$
a^{2}-a_{i}^{2}=\frac{6 k^{\prime} \dot{m} U_{\mathrm{o}}}{5 \pi}\left(t-t_{\mathrm{i}}\right)=\sigma\left(t-t_{\mathrm{i}}\right)
$$

190 The area of the cleared region, $A=\pi a^{2}$, is thus expected to increase linearly with time until $a$ reaches the position where the boundary layer becomes fully developed, denoted $r_{\mathrm{b}}$. Bhagat and Wilson ${ }^{14}$ reported that $r_{\mathrm{b}} / r_{\mathrm{o}}=0.48 R e^{1 / 3}$, where $R e$ is the Reynolds number in the jet. For the case in Figure $1, r_{\mathrm{b}}=7.5 \mathrm{~mm}$, and the corresponding value of $A$ is $176 \mathrm{~mm}^{2}$. Figure $1(f)$ shows that the measurements of the cleaned area extracted from the video stills exhibit the linear behaviour predicted by Equation [5].

A number of the Kaye et al. data sets were available for examination and will be shown to give good fits to Equation [5]. The model indicates that the effective cleaning rate constant obtained from such fits, $\sigma$, is related to the jet characteristics by 


$$
\sigma=\frac{6 k^{\prime} \dot{m} U_{\mathrm{o}}}{5 \pi}=\frac{6 k^{\prime} U_{\mathrm{o}}}{5 \pi} \rho \pi r_{\mathrm{o}}^{2} U_{\mathrm{o}}=\frac{6}{5} \rho k^{\prime}\left(r_{\mathrm{o}}^{2} U_{\mathrm{o}}^{2}\right)
$$

where $\rho$ is the liquid density. It should be noted that the parameter $\sigma$ is defined differently here 200 from ${ }^{17}$ for clarity, differing by a factor of 2.

(ii) Later stages or 'intermediate strength soil'

Kaye et al. presented one set of results (their Figure 4) in which $A$ increased as $t^{0.48}$. It will be demonstrated that this data set featured a large cleaned region (noticeably larger than many of the other data sets) such that $a>r_{\mathrm{b}}$ at longer times: $a$ then extends into the region where the 205 film flow is that of a viscous boundary layer. Integrating Equation [2] for this case gives

$$
c_{2}\left(a^{2}-a_{i}^{2}\right)+c_{3}\left(a^{5}-a_{i}^{5}\right)=\sigma\left(t-t_{\mathrm{i}}\right)
$$

with the parameters $c_{2}$ and $c_{3}$ given by

$$
\begin{aligned}
& c_{2}=1-\frac{10 \pi \mu}{3 \dot{m}} r_{\mathrm{o}} \\
& c_{3}=\frac{4 \pi \mu}{3 \dot{m} r_{\mathrm{o}}{ }^{2}}=\frac{4 \mu}{3 \rho U_{\mathrm{o}} r_{\mathrm{o}}{ }^{4}}=\frac{8}{3} \frac{1}{{r_{\mathrm{o}}}^{3}} R e^{-1}
\end{aligned}
$$

where $\mu$ is the liquid viscosity. Equation [7] indicates that at larger radii the second term on the LHS dominates and at large $a$ the cleaned area $\left(A=\pi a^{2}\right)$ is proportional to $t^{0.4}$, which is close to the behaviour reported by Kaye et al.

210 Kaye et al. also presented data for the area cleaned by a jet contacting a layer of soil on a rotating disc. The jet impinged the layer normally and created a ring of cleared material. Wilson et al..$^{19}$ presented a model for the area cleared at steady stage by a normally impinging jet moving in a straight line across a soil layer at velocity $V$, which Bhagat et al. (2017) modified for the strong soil case. The key elements of this are shown in Figure 2(a). Directly ahead of 215 the nozzle path, at location $\mathrm{X}$, distance $a_{\mathrm{x}}$ ahead of the centre of impingement, $\mathrm{O}$, the rate of cleaning is equal to the nozzle velocity. For a strong soil, at steady state,

$$
\left(\frac{\mathrm{d} a}{\mathrm{~d} t}\right)_{X}=\frac{\sigma}{2 a_{x}}=V
$$


At other positions on the cleaning front, e.g. point $\mathrm{P}$ associated with angle $\beta$, the cleaning front is located at radial distance $p$ from $\mathrm{O}$. The shape of the cleaning front is given by (see ${ }^{14}$ )

$$
\frac{\mathrm{d} p *}{\mathrm{~d} \beta}=\frac{1}{\sin \beta}-\frac{p *}{\tan \beta}
$$

where $p^{*}=p / a_{\mathrm{x}}$. When $a_{\mathrm{x}}>r_{\mathrm{o}}$, the boundary condition $p^{*}=1$ at $\beta=0$ yields the solution $p^{*}=$ $\beta \operatorname{cosec} \beta$ and the cleaning front grows in a quasi-elliptical shape, reaching a constant width at some distance downstream, of breadth $\pm \pi a_{\mathrm{x}}$ from the nozzle path. This will be an overestimate since at large values of $p$ the strong soil model will not be valid. The area cleared by the nozzle in Kaye et al.'s experiments can be modelled, to a first approximation, as a rectangular band of width $2 \pi a_{\mathrm{x}}$ and length $V\left(t-t_{\mathrm{i}}\right)$, giving

$$
A \approx \pi \sigma\left(t-t_{i}\right)
$$

225 which is effectively the same result as the static nozzle, to which could be added an extra component of order $\pi a_{x}^{2}$ representing the area cleared ahead and behind the nozzle. This result is compared with Kaye et al.'s data and modifications to the model are proposed for the case where $a_{\mathrm{x}}<r_{\mathrm{o}}$, which has not been considered previously.

\section{$230 \quad$ Results and Discussion}

\section{Evolution of cleaned area}

Nine sets of videos taken by Kaye et al. were available for analysis. Table 1 summarises the operating conditions used in each experiment. The Reynolds numbers indicate that the jets were all in the turbulent regime, while the Weber numbers $\left(W e_{\mathrm{G}}\right.$ and $W e_{\mathrm{L}}$ for the vapour and liquid phases, respectively) indicate that jet break-up would have involved the first or second windinduced regime ${ }^{20}$. The evolution of the radius of the cleaned area over time was extracted and compared with the above models. All the data sets inspected showed reasonable or good agreement with the model for a 'strong soil', Equation [5], which predicts that $a$ increases as $t^{0.5}$. Figure 3 shows three examples of results for different combinations of nozzle diameter and

240 jet velocities. The other profiles are provided as Supplementary Figures. One of these, Figure $\mathrm{S} 5$, shows a noticeable increase in gradient (and thus cleaning rate) after $4 \mathrm{~s}$, indicating a change 
in mechanism. This feature was not evident in the other video files available, however, and could not be investigated further.

The data were fitted to Equation [5], yielding an estimate of $\sigma$ for each case. Equation [6] indicates that $\sigma$ should be proportional to $\left(r_{\mathrm{o}} U_{\mathrm{o}}\right)^{2}$. The values are plotted in the from $\sigma^{1 / 2}$ against $r_{\mathrm{o}} U_{\mathrm{o}}$ in Figure 4 and show this linear dependency. From Equation [6], the gradient yields a $k^{\prime}$ value of $1.77( \pm 0.25) \times 10^{-5} \mathrm{~m} \mathrm{~s} \mathrm{~kg}^{-1}$. This is similar in magnitude to the values reported in ${ }^{13}$ for cleaning by impinging water jets at $20{ }^{\circ} \mathrm{C}$ using similar jet diameters and velocities at the lower end of the range in this study. Their values are reported here for comparison: $1.0 \times 10^{-5}$

$250 \mathrm{~m} \mathrm{~s} \mathrm{~kg}^{-1}$ for polyvinyl acetate layers, thickness $140 \mu \mathrm{m} ; 6.7 \times 10^{-6} \mathrm{~m} \mathrm{~s} \mathrm{~kg}^{-1}$ for petroleum jelly, thickness $250 \mu \mathrm{m} ; 2.0 \times 10^{-3} \mathrm{~m} \mathrm{~s} \mathrm{~kg}^{-1}$ for thin $(<80 \mu \mathrm{m})$ Xanthan gum layers. At the time of writing there is no theory available to predict $k^{\prime}$.

The good fit of these data to the model for a 'strong soil' appears to contradict the result presented by Kaye et al: their Figure 4 showed that the area of soil removed increased as $t^{0.48}$, 255 suggesting that $A=\pi a^{2} \propto t^{1 / 2}$ rather than $A \propto t$ (Equation [5]). This discrepancy can be explained by considering the conditions employed in the test in question. The data are reproduced in Figure 5. The original video and record of the experimental conditions were not available owing to issues with data storage. The early data lie near $r_{\mathrm{b}}$, where the viscous boundary layer is almost fully developed, beyond which Equation [5] is not expected to apply.

260 The Figure shows the prediction for Equation [7] using the value of $k^{\prime}$ obtained from Figure 4, as well as the result obtained by fitting Equation [7] to the data. The former underpredicts the observed cleaning rate, which could be due to differences in layer thickness or soil batch. Reasonable agreement is obtained using $k^{\prime}=13( \pm 0.9) \times 10^{-5} \mathrm{~m} \mathrm{~s} \mathrm{~kg}^{-1}$, which is approximately $7 \times$ the earlier value. A better fit to the data could be obtained with the more detailed numerical model in ${ }^{14}$ which models the transition in boundary layers more accurately than Equation [2].

\section{Cleaning efficiency}

Kaye et al. defined an efficiency factor, $E$, to quantify the performance of a cleaning process 


$$
E=\frac{\text { Area removed }}{\text { Volume of water used }}=\frac{\rho \pi a^{2}}{\dot{m} \cdot t}
$$

This is similar to the $E_{\mathrm{v}}$ parameter presented by Köhler et al. ${ }^{21}$. Kaye et al. reported the 270 following findings on how the nozzle diameter, jet velocity and exposure time affect $E$ for the overall process:

(i) $E$ increases with increasing exposure time up to a certain value but then decreases beyond this maximum;

(ii) $E$ increases as nozzle diameter is reduced;

(iii) $E$ increases with increasing jet velocity but this dependence is stronger for smaller nozzle diameters and weaker at long exposure times.

These findings are all consistent with the model for a 'strong soil'. Substituting Eq. [5] into [13] gives

$$
E=\left(\frac{\rho \pi}{\dot{m}}\right) \frac{a_{i}^{2}+\sigma\left(t-t_{i}\right)}{t}=\left(\frac{6 k^{\prime} \rho U_{0}}{5}\right) \frac{\frac{a_{i}^{2}}{\sigma}+t-t_{i}}{t}
$$

where $t_{i}$ is the induction time required for the jet to initially break through the layer. Kaye $e t$ $a l$. presented a surface plot of the dependency of $t_{i}$ on jet parameters $U_{\mathrm{o}}$ and $d_{N}$, which Kaye ${ }^{4}$ had modelled using the quadratic relationship

$$
t_{i}=C_{1}+C_{2} d_{N}+C_{3} d_{N}^{2}+C_{4} U_{\mathrm{o}}+C_{5} d_{N} U_{\mathrm{o}}+C_{6} U_{\mathrm{o}}^{2}
$$

in which $d_{N}$ is the nozzle diameter in $\mathrm{mm}$ and $U_{\mathrm{o}}$ is the jet velocity in $\mathrm{m} / \mathrm{s}$. The experimental fitting parameters $C_{1}$ to $C_{6}$ are given in Table 2 .

The surface plot of Eq. [15] in Figure 6 shows that $t_{i}$ increased modestly with increasing $d_{N}$, and decreased with increasing $U_{\mathrm{o}}$. [Kaye et al. erroneously reported the units of breakthrough time in their Figure as seconds rather than milliseconds]. At lower $d_{N}$ the decrease in $t_{i}$ is more modest than at higher nozzle diameters.

Equation [14] can also be written as 


$$
\begin{array}{ll}
E=0 & t \leq t_{\mathrm{i}} \\
E=E_{U}\left[1+\frac{\frac{a_{i}^{2}}{\sigma}-t_{i}}{t}\right] & t>t_{\mathrm{i}}
\end{array}
$$

where the prefactor $E_{\mathrm{U}}\left(\equiv \frac{6}{5} k^{\prime} \rho U_{o}\right)$ is determined by the soil and the jet velocity. If $a_{\mathrm{i}}^{2} / \sigma<t_{\mathrm{i}}$ the term in brackets increases with increasing $t$ so the efficiency increases at longer exposure times. Inspection of the videos indicates that $a_{\mathrm{i}} \approx d_{\mathrm{N}}$ (see Table 1 ), giving $a_{i}^{2} / \sigma \approx$ $10 /\left(3 \rho k^{\prime} U_{o}^{2}\right)$. For the $U_{\mathrm{o}}$ values tested, between 6 and $40 \mathrm{~m} \mathrm{~s}^{-1}$, the $k^{\prime}$ value of $1.8 \times 10^{-5} \mathrm{~m} \cdot \mathrm{s} \cdot \mathrm{kg}^{-}$ ${ }^{1}$ gives an estimate of $a_{i}^{2} / \sigma$ of $0.12-5.2 \mathrm{~s}$. The corresponding breakthrough times were 0.12 $-9.5 \mathrm{~s}$, confirming that $a_{\mathrm{i}}^{2} / \sigma-t_{\mathrm{i}}$ is negative.

295 At longer times Equation [7] applies and $a \approx \sqrt[5]{\frac{\sigma}{c_{3}} t}$. The corresponding expression for $E$ is then

$$
E=\frac{\rho \pi}{\dot{m}} \frac{\left(\frac{\sigma}{c_{3}} t\right)^{2 / 5}}{t}=\left(\frac{9}{10} \frac{k^{\prime}}{\mu} \sqrt{\frac{\rho^{3} \dot{m}}{\pi}}\right)^{2 / 5} t^{-3 / 5}
$$

and $E$ decreases at longer times, confirming finding (i), of an observed maximum in $E$. A detailed calculation of this transition for an example case is provided in Figure 7.

Expression [16b] also explains finding (ii). The induction time decreases for smaller nozzle diameters (see Figure 6) increasing the term in brackets in Eq. [16b] and thereby the efficiency.

300 The nozzle diameter affects both $a_{\mathrm{i}}$ and $\sigma: a_{\mathrm{i}} \propto d_{\mathrm{N}}$ (and $r_{\mathrm{o}}$ ), while $\sigma \propto \dot{m}\left(=\rho \pi r_{\mathrm{o}}{ }^{2} U_{\mathrm{o}}\right.$ ), so these cancel each other out.

Finding (iii) can also be explained by $E_{U}$ being proportional to $U_{\mathrm{o}}$, which results in a higher efficiency for larger jet velocities. The reason why this effect is stronger for smaller nozzle diameters is the dependence of $t_{i}$ on $U_{\mathrm{o}}$ and $d_{\mathrm{N}}$ in Equation [15]: for the parameter range investigated by Kaye et al. the induction time was shorter for smaller nozzles.

Kaye et al. also analysed the efficiency for the peeling process alone, i.e. after the liquid jet penetrates the soil layer. For this case they reported the following three experimental observations:

(i) $E$ decreases with increasing the exposure time; 
(iii) $E$ is roughly independent on the jet velocity.

These results can be explained by the 'strong soil' model with $t_{\mathrm{i}}$ set to zero. Substituting for $\dot{m}=\pi r_{\mathrm{o}}^{2} U_{\mathrm{o}} \rho$ and $\sigma$ yields

$$
E=\frac{6}{5} \rho k^{\prime} U_{\mathrm{o}}+\frac{a_{i}^{2}}{r_{\mathrm{o}}^{2} U_{\mathrm{o}} t}=E_{u}+\frac{a_{i}^{2}}{r_{\mathrm{o}}^{2} U_{\mathrm{o}} t}
$$

If $a_{i} \approx r_{\mathrm{o}}$

$$
E=E_{u}+\frac{1}{U_{\mathrm{o}} t}
$$

315 Figure 8 displays the efficiency of the peeling process, calculated using Eq. [19], as a function of $t, d_{N}$ and $U_{\mathrm{o}}$ for the parameter space reported by Kaye et al. Observations (i) and (iii) are predicted but observation ( $i i)$ is not, primarily due to the assumption that $a_{i} \approx r_{\mathrm{o}}$. Values of $a_{i}$ extracted from the available video records are reported in Table 1 . The ratio $a_{\mathrm{i}} / r_{\mathrm{o}}$ is larger for the smaller nozzle diameters, explaining the higher efficiency in these cases and confirming observation (ii).

\section{Moving nozzle}

Kaye et al. studied the effect of the nozzle (and jet impingement point) moving across a soiled plate using a $d_{\mathrm{N}}=1 \mathrm{~mm}$ nozzle, $U_{\mathrm{o}}=30.5 \mathrm{~m} \mathrm{~s}^{-1}$ water jet with traverse speeds ranging from 5 to $20 \mathrm{~mm} \mathrm{~s}^{-1}$. The motion was achieved by rotating a coated disk. Tests employed a common exposure time of $2 \mathrm{~s}$. The induction time for a static nozzle was $153 \pm 7 \mathrm{~ms}$. Their data are reproduced as Figure 9 and show that a static nozzle cleared an area of approximately $30 \mathrm{~mm}^{2}$. This compares favourably with $A$ predicted by Equation [5] using $a_{\mathrm{i}}=r_{\mathrm{o}}=0.5 \mathrm{~mm}$ and $k^{\prime}=$ $1.8 \times 10^{-5} \mathrm{~m} \cdot \mathrm{s} \cdot \mathrm{kg}^{-1}\left(\sigma=5 \times 10^{-6} \mathrm{~m}^{2} \mathrm{~s}^{-1}\right)$ of $29.9 \mathrm{~mm}^{2}$.

330 Figure 9 shows that the cleared area increased linearly with $V$ until around $10 \mathrm{~mm} \mathrm{~s}^{-1}$, after which it decreased strongly with $V$. The latter trend was attributed by Kaye et al. to incomplete breakthrough of the soil layer by the jet, which we term a ballistic regime. The time for which 
an element of soil is exposed to the direct impingement of water (promoting breakthrough) can be estimated as $d_{\mathrm{N}} / V$, giving $100 \mathrm{~ms}$ for the critical velocity of $10 \mathrm{~mm} \mathrm{~s}^{-1}$. This is comparable in magnitude to the $t_{\mathrm{i}}$ value reported above, but suggests that the footprint of the jet is slightly larger than $0.8 \mathrm{~mm}^{2}\left(=\pi a_{\mathrm{i}}^{2}\right.$ with $a_{\mathrm{i}}=0.5 \mathrm{~mm}$ ), at $1.8 \mathrm{~mm}^{2}$ (calculated from $2 a_{\mathrm{i}}=210 \mathrm{~mm} \mathrm{~s}^{-1} \times$ $0.15 \mathrm{~s}$, giving $a_{\mathrm{i}}=0.75 \mathrm{~mm}$ ). Increasing $a_{\mathrm{i}}$ from $0.5 \mathrm{~mm}$ to $0.75 \mathrm{~mm}$ would change the predicted value of $A$ for the static nozzle to $30.9 \mathrm{~mm}^{2}$, which lies within the spread of data. The value of $a_{\mathrm{i}}$ measured in the static nozzle experiment (Table 1) was around $1 \mathrm{~mm}$, which is consistent with the above finding. The reduction in $A$ with increasing $V$ cannot be explained by the peeling model (Equation [1]) as the model requires the peeling front to have been established and momentum overcomes the soil-substrate adhesive force. The mechanisms active in this ballistic regime, where the jet is penetrating the soil layer, have not been fully established, and represents a topic for further work.

345 The moving nozzle result (Equation [12]) does not predict the observed increase in $A$ with $V$ : this expression gives $A=29 \mathrm{~mm}^{2}$. Inspection of the $a_{\mathrm{x}}$ values (calculated from $a_{\mathrm{x}}=\sigma / 2 \mathrm{~V}$, Equation [10]), however, indicates that $a_{\mathrm{x}}=r_{\mathrm{o}}$ at $V=5 \mathrm{~mm} \mathrm{~s}^{-1}$. At steady state, for this and higher velocities, the peeling front would lie within the nozzle footprint, which is inconsistent with the expression used to estimate the momentum, $M$. In effect the nozzle is moving faster than the peeling front given by the model, indicating that the existing model is not valid (as it requires that $a \geq r_{\mathrm{o}}$ ).

We term this 'very strong soil' behaviour and propose an amendment of the model to account for the overlap with the initial ballistic step. Figure 2(b) shows the key features. Along arc XB, where the initial penetration step determines removal, the cleaning front is assumed to be circular, with radius $a_{\mathrm{i}}{ }^{*}=a_{\mathrm{i}} / a_{\mathrm{x}}$. Beyond $\mathrm{B}$, in the nozzle's wake, peeling - described by Equation [1] - extends the initially circular crater. Equation [11] applies, with boundary condition $p^{*}=a_{\mathrm{i}}^{*}$ at $\beta=\pi / 2$. The solution is

$$
p^{*}=\left(a_{i}^{*}+\beta-\pi / 2\right) \operatorname{cosec} \beta
$$

and the dimensionless half-width of the cleared track approaches $a_{\mathrm{i}}^{*}+\pi / 2$ as $\beta \rightarrow \pi$. Figure $2(b)$ shows the shape of the cleared front for two values of $a_{\mathrm{i}}{ }^{*}$, of 1 and 2 . It can be seen that 360 the width of the cleared zone downstream of $\mathrm{O}$ changes less as $a_{\mathrm{i}}^{*}$ increases, corresponding to the soil becoming stronger. 
The area of a rectangular strip thus cleared (neglecting the contributions from each end) is then

$$
A=2\left(a_{i}^{*}+\frac{\pi}{2}\right) a_{x} V\left(t-t_{i}\right)
$$

or, in dimensional form,

$$
A=(\underbrace{2 a_{i} V}_{\text {milling }}+\underbrace{\frac{\pi}{2} \sigma}_{\text {peeling }})\left(t-t_{i}\right)
$$

The expression can be interpreted as containing a 'milling' contribution, where the soil is cleared away from the immediate jet footprint, and a peeling contribution. The milling term dominates as $V$ increases, as observed in the experiments, until the ballistic limit is reached. The expression is not expected to apply when $a_{\mathrm{i}}<a_{\mathrm{x}}$ as peeling augments the milling step ahead of the nozzle. Including an estimated contribution from the leading and trailing ends gives

$$
A=\pi a_{i}^{2}+\left(2 a_{i} V+\frac{\pi}{2} \sigma\right)\left(t-t_{i}\right)
$$

This model has one adjustable parameter, $a_{\mathrm{i}}$, which is subject to the constraint $a_{\mathrm{i}}>r_{\mathrm{o}}$. The 370 behaviour predicted for a range of viable $a_{\mathrm{i}}$ values is plotted alongside the experimental data in Figure 9. It can be seen that setting $a_{\mathrm{i}}=1.2 \mathrm{~mm}$ gives good agreement with Kaye et al.'s results. The loci are plotted for velocities in the expected range of validity, namely $\sigma /\left(2 a_{\mathrm{i}}\right) \leq V$ $\leq 10 \mathrm{~mm} \mathrm{~s}^{-1}$, and it can be seen that there is a smooth transition from the strong soil result for the $a_{\mathrm{i}}=1.2 \mathrm{~mm}$ locus. Unfortunately, Kaye et al. did not investigate this range of velocities so the transition behaviour cannot be confirmed.

The validity of the model could also be determined by comparing the shape of the cleared region with that predicted by the model. Photographs of the cleared region from Kaye (1995) were inspected and the aspect ratio (length/width) calculated. The results are plotted alongside the model predictions for different values of $a_{\mathrm{i}}$ in Supplementary Figure S10. There is again reasonably good agreement for $a_{\mathrm{i}}=1.2 \mathrm{~mm}$. This difference between $a_{\mathrm{i}}$ and $r_{\mathrm{o}}$ is consistent with the results reported by other workers ${ }^{7,12,22,23}$ for jet impingement on a variety of soils.

Extension of the results to industrial practice will require consideration of features such as jet break-up $\left(e . g .{ }^{24}\right)$ and oblique impingement. The effect of oblique impingement has been 
discussed for weak and strong soils by Bhagat et al. ${ }^{17}$, while Hand et al. ${ }^{11}$ investigated oblique impingement in the ballistic regime by impinging jets as a way of studying erosion by high velocity droplets.

\section{Conclusions}

A modest number of the original video records and several of the data sets collected by Kaye

390 et al. in their investigation of cleaning by an impinging liquid jet have been re-examined and compared with the quantitative cleaning models presented by Bhagat et al. ${ }^{17}$. The data show that the soil exhibited the 'strong soil' behaviour, and the anomalous data set could be explained as featuring the transition to Bhagat et al.'s 'intermediate soil' behaviour. The quantitative understanding provided by the model is able to predict the effect of process parameters on the cleaning efficiency reported by Kaye et al.

The performance of a moving nozzle reported by Kaye et al. did not match the 'strong soil' prediction of Bhagat et al. Inspection of the data indicated that this was due to the tests featuring traverse velocities that invalidated one of the assumptions of the Bhagat et al. model. In this 'strong soil' regime the area cleared by the impinging jet in its initial scouring stage as

400 it penetrates the layer dominates. This 'very strong soil' behaviour requires the model to be modified to describe the milling action of a fast moving nozzle. The new model gave very satisfactory agreement with the measurements of the cleared area and its shape.

The results provide a quantitative mechanistic account of Kaye et al.'s findings and offer a route to design or understand the cleaning performance of jets from moving nozzles based on simpler experiments with a stationary nozzle.

\section{Open Data}

A statement relating to access to the data at the University of Cambridge Apollo data repository will be included here if the manuscript is accepted for publication.

410 


\section{ACKNOWLEDGEMENTS}

ERASMUS funding for DO from the European Union, $\mathrm{PhD}$ scholarships for RKB and RRF from the Commonwealth Scholarship Commission and CAPES-Brazil, respectively, are all

415 gratefully acknowledged, as is permission from Unilever to publish the data and the assistance of Dr Peter Kaye in retrieving data from his $\mathrm{PhD}$ work. 


\section{References}

[1] Fryer, P.J. and Asteriadou, K. A prototype cleaning map: A classification of industrial cleaning processes, Trends Food Sci Tech., 20(6-7) (2009) 255-262. DOI: 10.1016/j.tifs.2009.03.005

[2] Yeckel, A, and Middleman, S. Removal of a viscous film from a rigid plane surface by an impinging liquid jet. Chem. Eng. Comm. 50(1-6) (1987) 165-175. DOI: $10.1080 / 00986448708911823$

425 [3] Briscoe, B.J., Pickles, M.J., Julian, K.S. and Adams, M.J. Erosion of polymer-particle composite coatings by liquid water jets, Wear, 203-4 (1997) 88-97. DOI: 10.1016/S00431648(96)07379-6

[4] Kaye, P.L. The erosive cleaning of surfaces, (1995) $\mathrm{PhD}$ dissertation, University of Cambridge.

430 [5] Jiang, H., Du, C. and Liu, Z. Theoretical and numerical investigation on rock fragmentation under high-pressure water-jet impact. Iranian J. Sci. Tech., Trans. Civil Eng., 41(3), (2017) 305-315. DOI: 10.1007/s40996-017-0065-0

[6] Mabrouki, T., Raissi, K. and Cornier, A. Numerical simulation and experimental study of the interaction between a pure high-velocity waterjet and targets: Contribution to investigate the decoating process. Wear, 239(2) (2000) 260-273. DOI: 10.1016/S0043-1648(00)003331

[7] Aderibigbe, O.O. and Rajaratnam, N. Erosion of loose beds by submerged circular impinging vertical turbulent jets. J. Hydraulic Res. 34(1) (1996) 19-33. DOI: $10.1080 / 00221689609498762$

440 [8] Bowden, F.P. and Field, J.E. The brittle fracture of solids by liquid impact, by solid impact, and by shock. Proc. Royal Soc. A, 282(1390) (1964) 331-352. DOI: 10.1098/rspa.1964.0236

[9] Kaye, P.L., Pickles, C.S.J., Field, J.E. and Julien, K.S. Investigation of erosion processes as cleaning mechanisms in the removal of thin deposited soils, Wear, 186-187 (1995) 413420. DOI: 10.1016/0043-1648(95)07152-0

[10] Taştan, K., Koçak, P. P. and Yildirim, N. Effect of the bed-sediment layer on the scour caused by a jet, Arabian J. Sci. Eng., 41(10) (2016) 4029-37. DOI: 10.1007/s13369-0162093-7

[11] Hand, R.J., Field, J.E. and Townsend, D. The use of liquid jets to simulate angled drop impact, J. Appl. Phys. 70, 1991, 7111-7118. DOI: 10.1063/1.349793

[12] Rose, C.W., Olley, J.M., Haddadchi, A., Brooks, A.P. and McMahon, J. An alternative method for interpreting jet erosion test (JET) data: part 1. Theory. Earth Surf. Process. Landforms, 43 (2018) 735-742. DOI: 10.1002/esp.4269

[13] Wilson, D.I., Atkinson, P., Köhler, H., Mauermann, M., Stoye, H., Suddaby, K. Wang, T., Davidson, J.F. and Majschak, J.-P. Cleaning of soft-solid soil layers on vertical and 
horizontal surfaces by coherent impinging liquid jets. Chem. Eng. Sci, 109 (2014) 183-196. DOI: 10.1016/j.ces.2014.01.034

[14] Bhagat, R.K. and Wilson, D.I. Flow in the thin film created by a coherent turbulent water jet impinging on a vertical wall, Chem. Eng. Sci. 152 (2016) 606-623. DOI: 10.1016/j.ces.2016.06.011

[15] Bhagat, R.K., Jha, N.K., Linden, P.F. and Wilson, D.I. On the origin of the hydraulic jump in a thin liquid film, J. Fluid Mech. 851, R5. (2018) DOI: 10.1017/jfm.2018.558

[16] Meng, P., Geskin, E.S., Leu, M.C., Li, F. and Tismeneskiy, L. An analytical and experimental study of cleaning with moving water jets, J. Manuf. Sci. Eng., 120 (1998) 580589. DOI: $10.1115 / 1.2830162$

[17] Bhagat, R.K., Perera, A.M. and Wilson, D.I. Cleaning tank walls by moving water jets: simple models and supporting experiments, Food Bioprod. Proc, 102, (2017) 31-54. DOI: 10.1016/j.fbp.2016.11.011

[18] Wilson, D.I., He, B.L., Dao, H.D.A, Lai, K.Y., Morison, K.R. and Davidson, J.F. Surface flow and drainage films created by horizontal impinging liquid jets, Chem. Eng. Sci, 68 (2012) 449-460. DOI: 10.1016/j.ces.2011.10.003

[19] Wilson, D.I., Köhler, H., Cai, L., Majschak, J-P. and Davidson, J.F. Cleaning of a model food soil from horizontal plates by a moving vertical water jet, Chem. Eng. Sci. 123 (2015) 450-459. DOI: 10.1016/j.ces.2014.11.006

475 [20] Lin, S.P. and Reitz, R.D. Drop and spray formation from a liquid jet, Ann. Rev. Fluid Mech., 30 (1998) 85-105. DOI: 10.1146/annurev.fluid.30.1.85

[21] Köhler, H., Stoye, H., Mauermann, M., Weyrauch, T. and Majschak, J.-P. How to assess cleaning? Evaluating the cleaning performance of moving impinging jets, Food Bioprod. Proc, 93 (2015) 327-332. DOI: 10.1016/j.fbp.2014.09.010

480 [22] Haddadchi, A., Rose, C.W., Olley, J.M., Brooks, A.P., McMahon, J. and Pietsch, T. An alternative method for interpreting JET erosion test (JET) data: Part 2. Application. Earth Surf. Process. Landforms, 43, (2018) 743-754. DOI: 10.1002/esp.4270

[23] Mazurek, K.A., Rajaratnam, N., and Sego, D.C. Scour of cohesive soil by submerged circular turbulent impinging jets. J. Hydraul. Eng. 127 (2001) 598-606. DOI: 10.1061/(ASCE)0733-9429(2001)127:7(598).

[24] Chee, M.W.L., Ahuja, T.V., Bhagat, R.K., Taesopapong, N., Wan, S.A., Wigmore, R.L. and Wilson, D.I. Impinging jet cleaning of tank walls: Effect of jet length, wall curvature and related phenomena, Food Bioprod. Proc, (2019) in press, DOI: 10.1016/j.fbp.2018.10.005 


\section{Tables}

Table 1 -Summary of operating conditions in the experiments analysed.

\begin{tabular}{cccccccc}
\hline $\begin{array}{c}d_{\mathrm{N}}^{\dagger} \\
{[\mathrm{mm}]}\end{array}$ & $\begin{array}{c}Q \\
{\left[\mathrm{~m}^{3} \mathrm{~s}^{-1} \times 10^{-6}\right]}\end{array}$ & $\begin{array}{c}U_{\mathrm{o}} \\
{\left[\mathrm{m} \mathrm{s}^{-1}\right]}\end{array}$ & $R e$ & $\begin{array}{c}L \\
{[\mathrm{~m}]}\end{array}$ & $W e_{L}$ & $W e_{G}$ & $\begin{array}{c}a_{i} \\
{[\mathrm{~mm}]}\end{array}$ \\
\hline 0.25 & 0.98 & 19.9 & 4975 & 0.1 & 1370 & 1.65 & 0.41 \\
0.35 & 1.09 & 11.3 & 3955 & 0.1 & 620 & 0.74 & 0.47 \\
0.35 & 2.69 & 28.0 & 9800 & 0.1 & 3810 & 4.57 & 0.50 \\
1.00 & 4.71 & 6.0 & 6000 & 0.1 & 500 & 0.60 & 1.05 \\
1.00 & 15.63 & 19.9 & 19900 & 0.1 & 5500 & 6.60 & 0.93 \\
1.00 & 23.95 & 30.5 & 30500 & 0.1 & 12900 & 15.50 & 0.97 \\
1.50 & 23.86 & 13.5 & 20250 & 0.1 & 3797 & 4.56 & 1.48 \\
1.50 & 49.48 & 28.0 & 42000 & 0.1 & 16300 & 19.60 & 1.57 \\
2.00 & 61.26 & 19.5 & 39000 & 0.1 & 10600 & 12.68 & 1.99 \\
\hline
\end{tabular}

$495 \uparrow$ The jet diameter is assumed to be equal to the nozzle diameter, i.e. $r_{\mathrm{o}}=d_{\mathrm{N}} / 2$

Table 2 - Experimental constants in Eq. [15], reproduced from Kaye (1995) with permission.

\begin{tabular}{cc}
\hline Constant & Value \\
\hline$C_{1}$ & $6.00 \mathrm{~s}$ \\
$C_{2}$ & $5.44 \mathrm{~s} \mathrm{~mm}^{-1}$ \\
$C_{3}$ & $-0.23 \mathrm{~s} \mathrm{~mm}^{-2}$ \\
$C_{4}$ & $-0.74 \mathrm{~s}^{2} \mathrm{~m}^{-1}$ \\
$C_{5}$ & $-0.23 \mathrm{~s}^{2} \mathrm{~mm}^{-1} \mathrm{~m}^{-1}$ \\
$C_{6}$ & $0.02 \mathrm{~s}^{3} \mathrm{~m}^{-2}$ \\
\hline
\end{tabular}


(a)

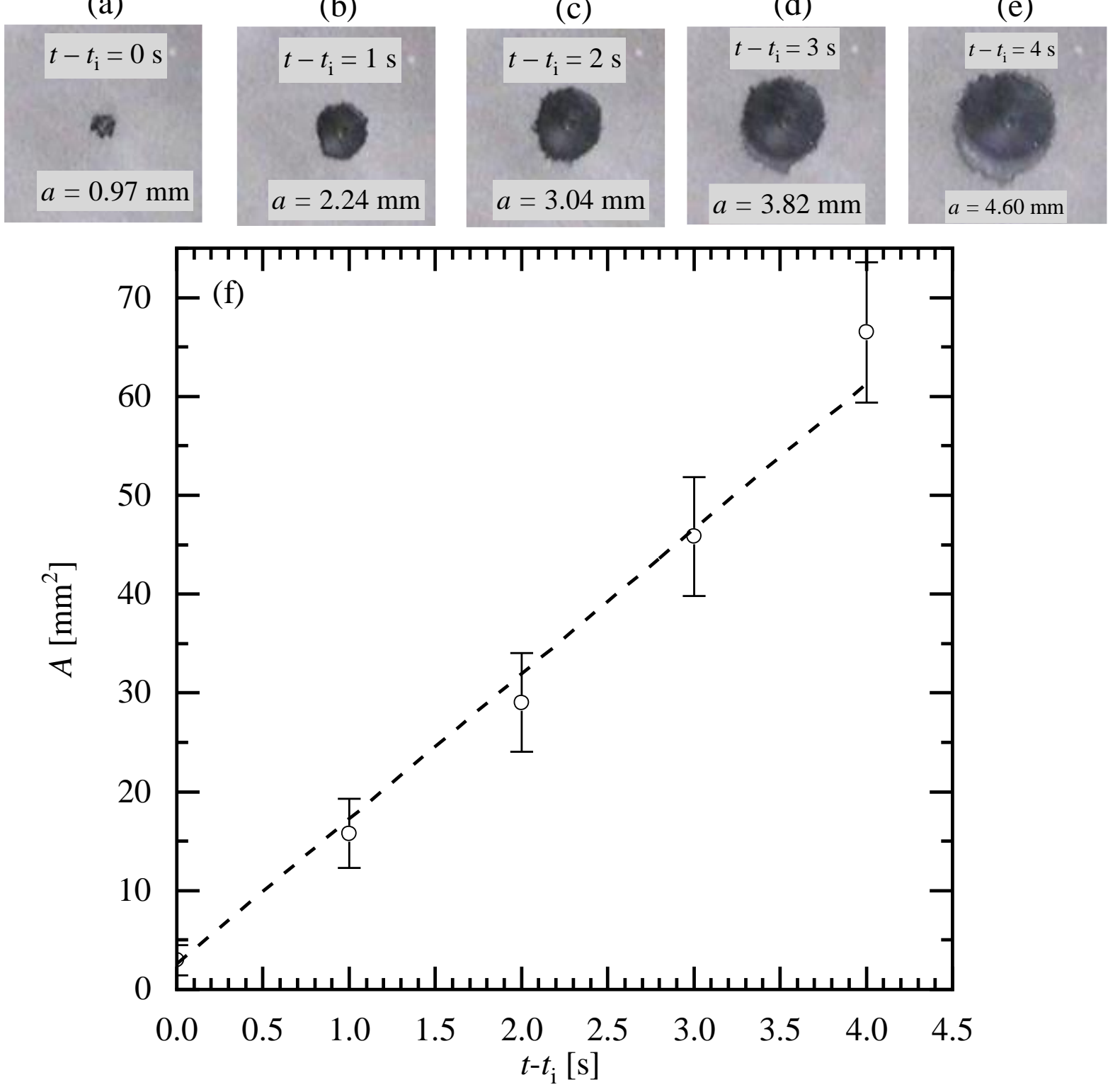

Figure 1. Growth of the cleaned region at salient times after breakthrough for a water jet of diameter $1 \mathrm{~mm}$ and mean velocity $30.5 \mathrm{~m} \mathrm{~s}^{-1}$. (a-e) images captured from the video file provided by P.L. Kaye at times indicated; $(f)$ change in cleaned area with time, plotted in the form used by Kaye et al. (1995). 
(a)

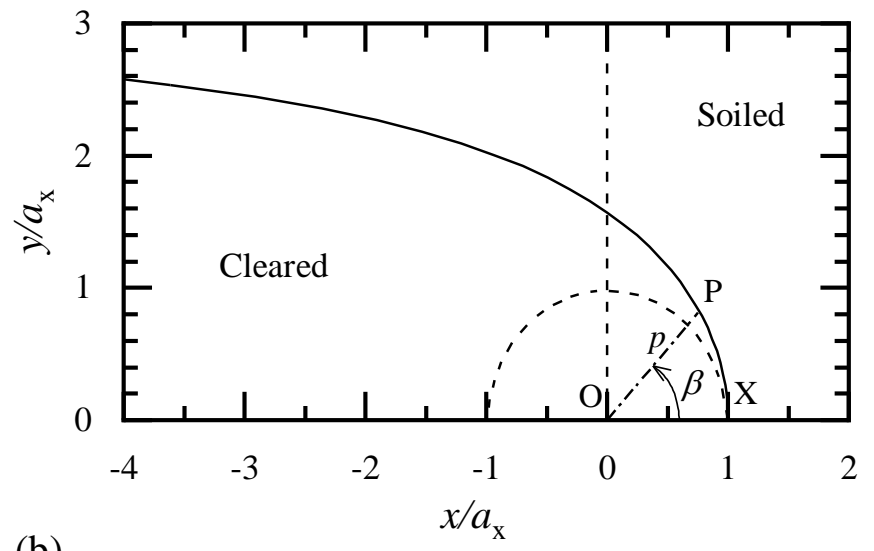

(b)

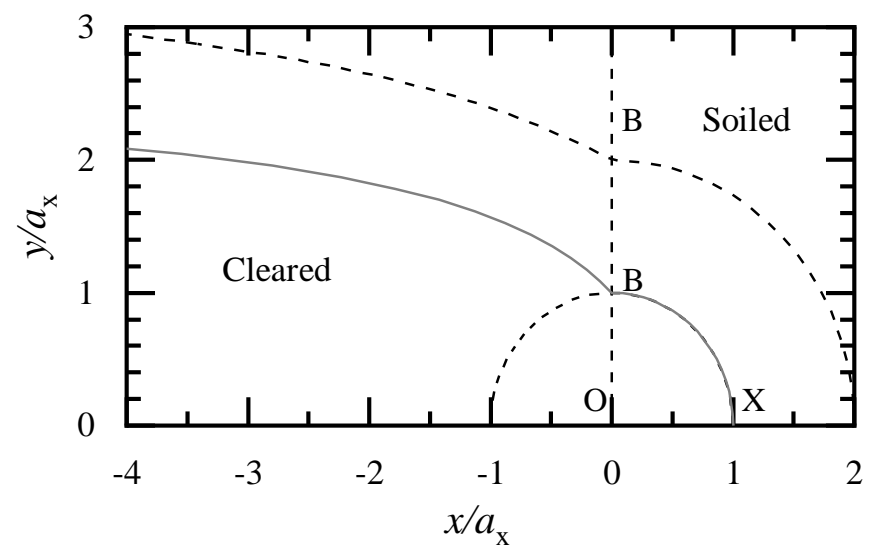

Figure 2. Shape of the cleaning front cleared by moving nozzle in Cartesian co-ordinates, scaled by $a_{\mathrm{x}}$, for ( $a$ ) the 'strong soil' case, where $a_{\mathrm{x}}>r_{\mathrm{o}}$, and $(b)$ the 'very strong soil', where $a_{\mathrm{x}} \leq r_{\mathrm{o}}$, for the case where $(\mathrm{i}) a_{\mathrm{i}}=a_{\mathrm{x}}$ (solid grey line), and (ii) $a_{\mathrm{i}}=2 a_{\mathrm{x}}$ (dashed line). Dot-dashed lines in each plot show $x=0$ and the circle, radius $a_{\mathrm{x}}$, centred at $\mathrm{O}$. 


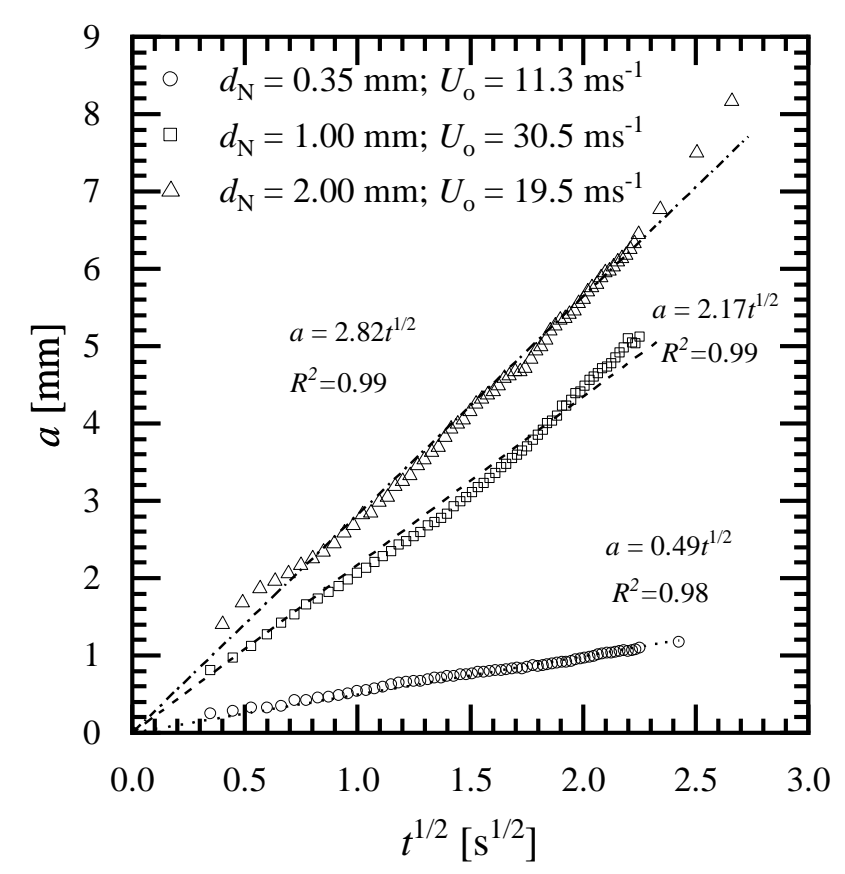

515 Figure 3. Evolution of average cleaned radius with time presented in the form predicted by Equation [5]. $R^{2}$ is the regression coefficient. 


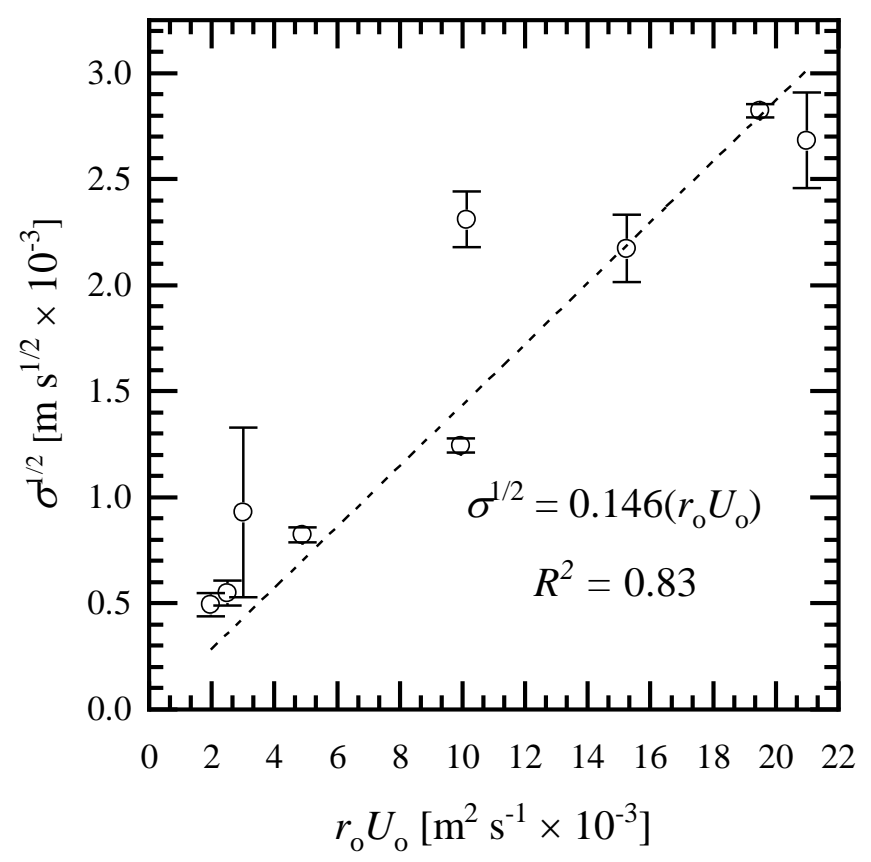

520 Figure 4. Effect of $r_{\mathrm{o}} U_{\mathrm{o}}$ on gradient of cleaning profiles for all videos analysed in this work. [Data are reported in Table S1.] 


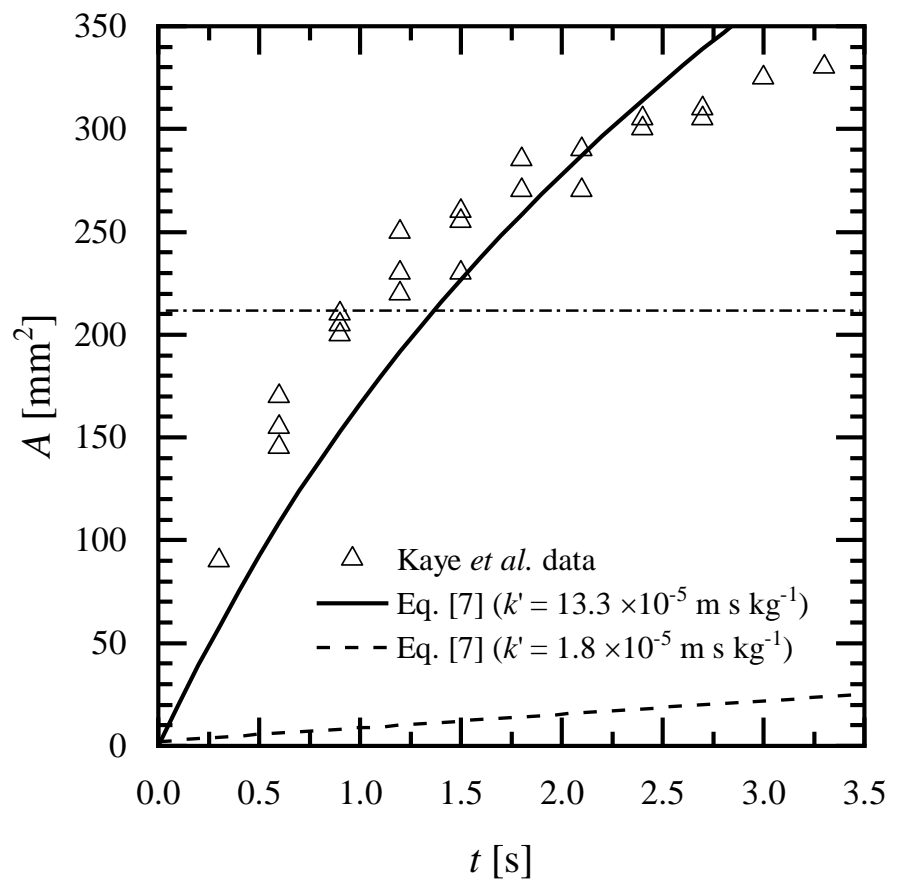

Figure 5. Cleaning profile reported in Kaye et al. (1995), Figure 4, for a water jet of diameter 525 $1 \mathrm{~mm}$ and mean velocity $40 \mathrm{~m} \mathrm{~s}^{-1}$. Dot-dashed line shows area corresponding to $r_{\mathrm{b}}$, here $8.2 \mathrm{~mm}$. Solid and dashed loci show behaviour predicted by Eq. [7] for $k^{\prime}$ values shown. 


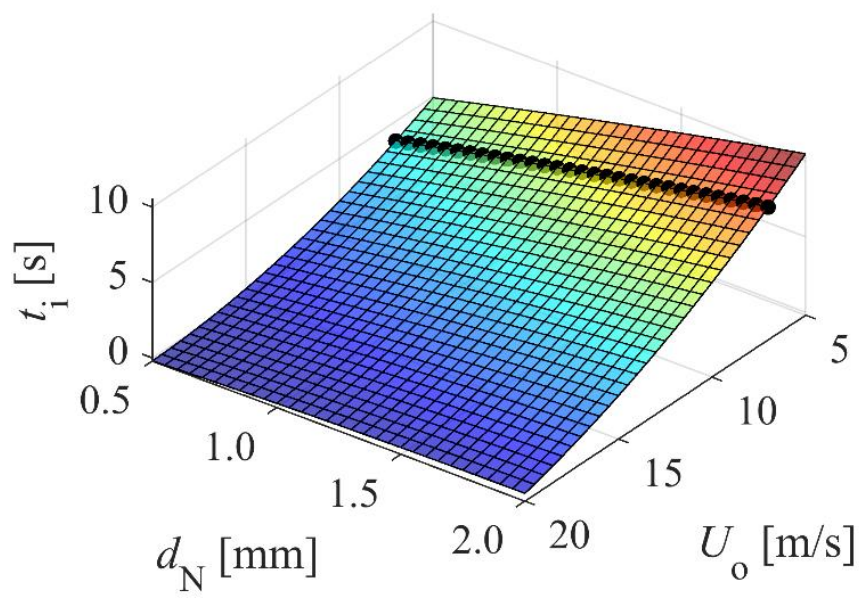

Figure 6. Effect of $d_{\mathrm{N}}$ and $U_{\mathrm{o}}$ on induction time for a static nozzle. Black circles show the trend for a jet with $U_{\mathrm{o}}=7 \mathrm{~m} \mathrm{~s}^{-1}$, as an example. Note $U_{\mathrm{o}}$ axis has decreasing scale. 


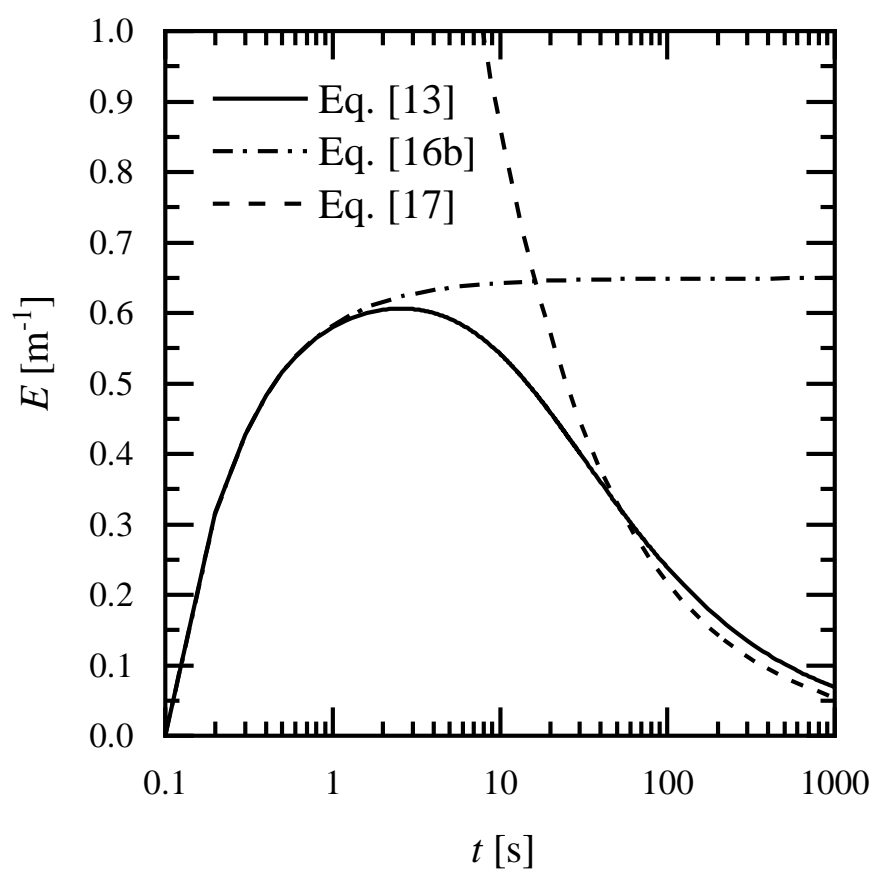

Figure 7. Effect of time on cleaning efficiency for nozzle with $d_{\mathrm{N}}=1 \mathrm{~mm}$ and $U_{\mathrm{o}}=30.5 \mathrm{~m} \mathrm{~s}^{-1}$. Loci show the behaviour for (i) solid line - $A$ calculated using Eq. [7], evaluated numerically; (ii) dot-dash line - short exposure time, 'strong soil', Eq. [16b], and (iii) dashed line, longer exposure times, 'intermediate strength soil', Eq. [17]. 
(a)
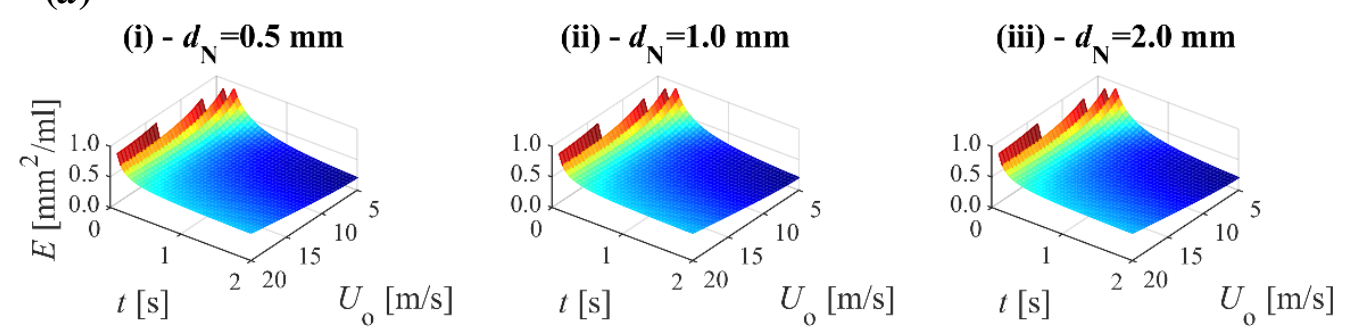

(b)
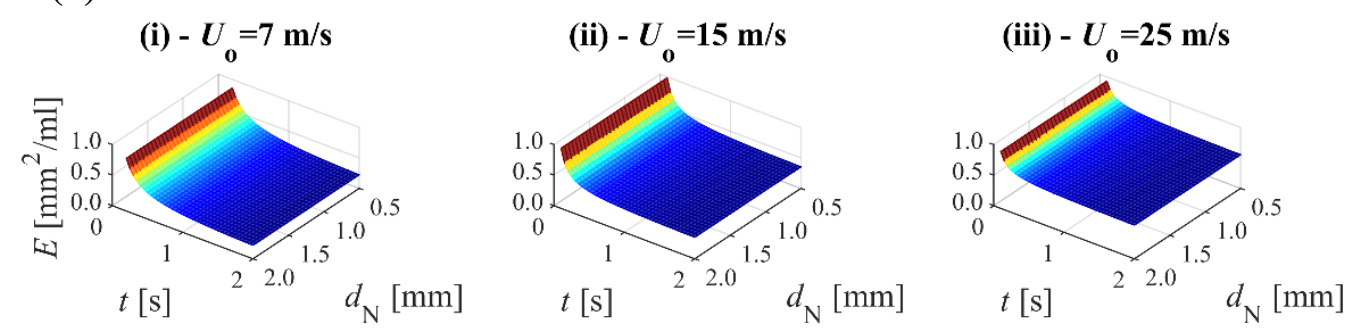

Figure 8. Surface plots of the cleaning efficiency for the peeling process. (a - i to iii) $E$ as a function of $t$ and $U_{\mathrm{o}}$ for different values of $d_{\mathrm{N}}$; (b - i to iii) $E$ as a function of $t$ and $d_{\mathrm{N}}$ for different values of $U_{\mathrm{o}}$. 


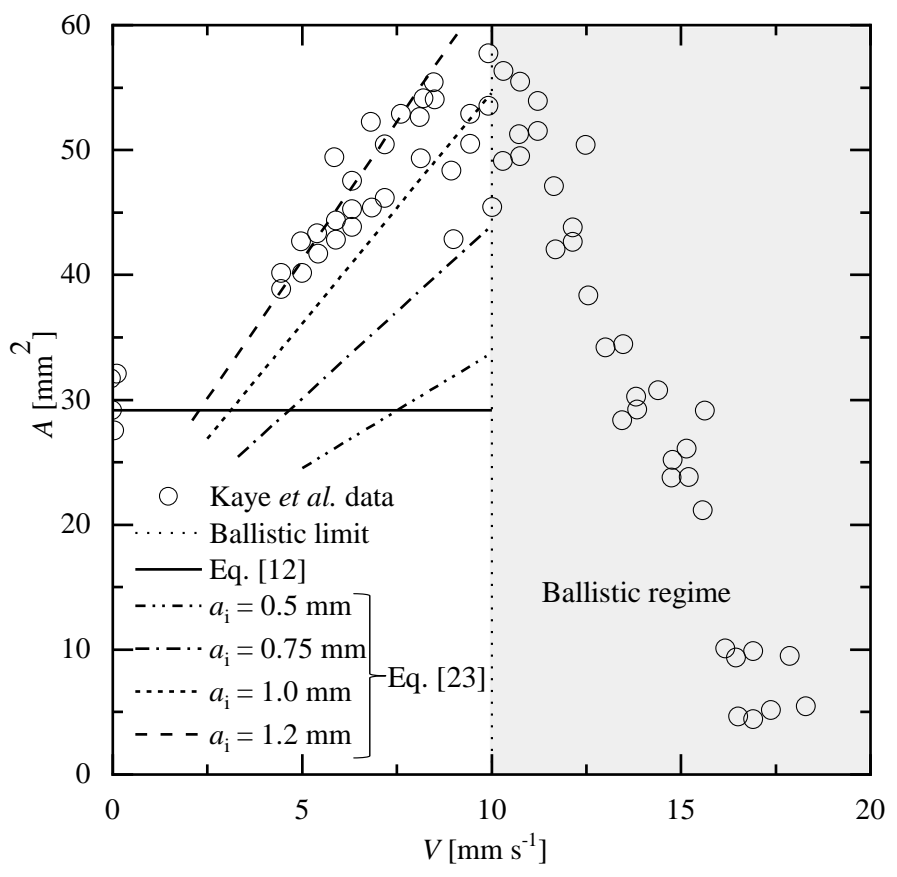

Figure 9. Effect of nozzle velocity on cleared area. $d_{\mathrm{N}}=1 \mathrm{~mm}, U_{\mathrm{o}}=30.5 \mathrm{~mm} \mathrm{~s}^{-1}$, data extracted from Kaye et al. (1995). Vertical dotted line marks transition from a peeling to a penetration-limited regime, as suggested by Kaye et al. Solid line shows predicted behaviour for a 'strong soil' (Eq. [12]), and dashed loci show the predictions for a 'very strong soil' (Eq. [23]) for indicated initial cleared radius $a_{\mathrm{i}}$. 


\section{Supplementary Figures}

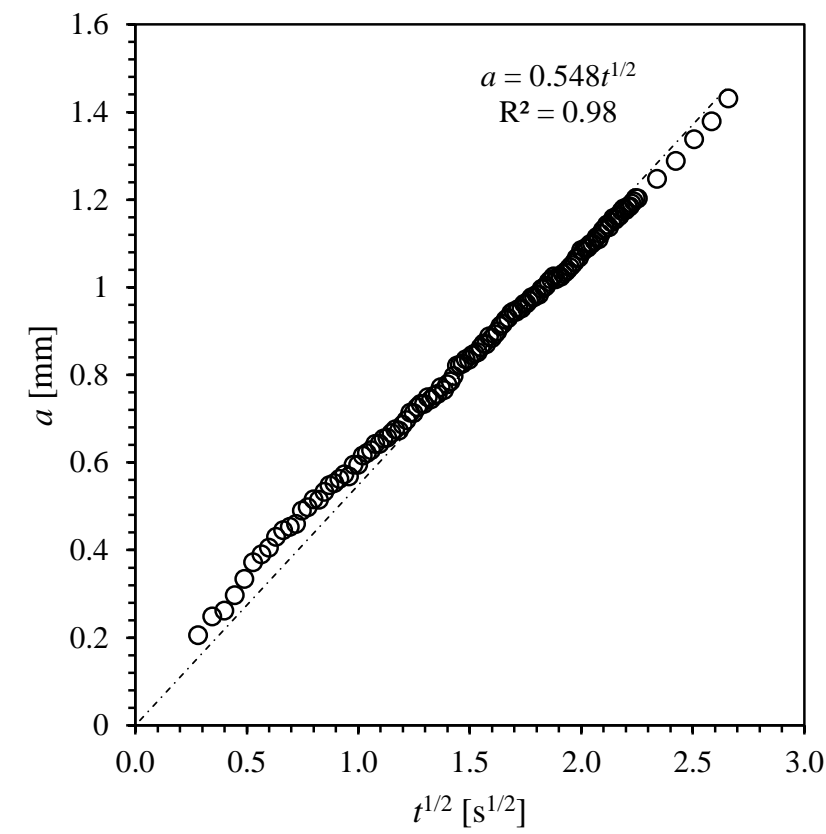

Figure $\mathrm{S} 1-$ Evolution of cleaning front for $d_{\mathrm{N}}=0.25 \mathrm{~mm}, U_{\mathrm{o}}=19.9 \mathrm{~m} \mathrm{~s}^{-1}$

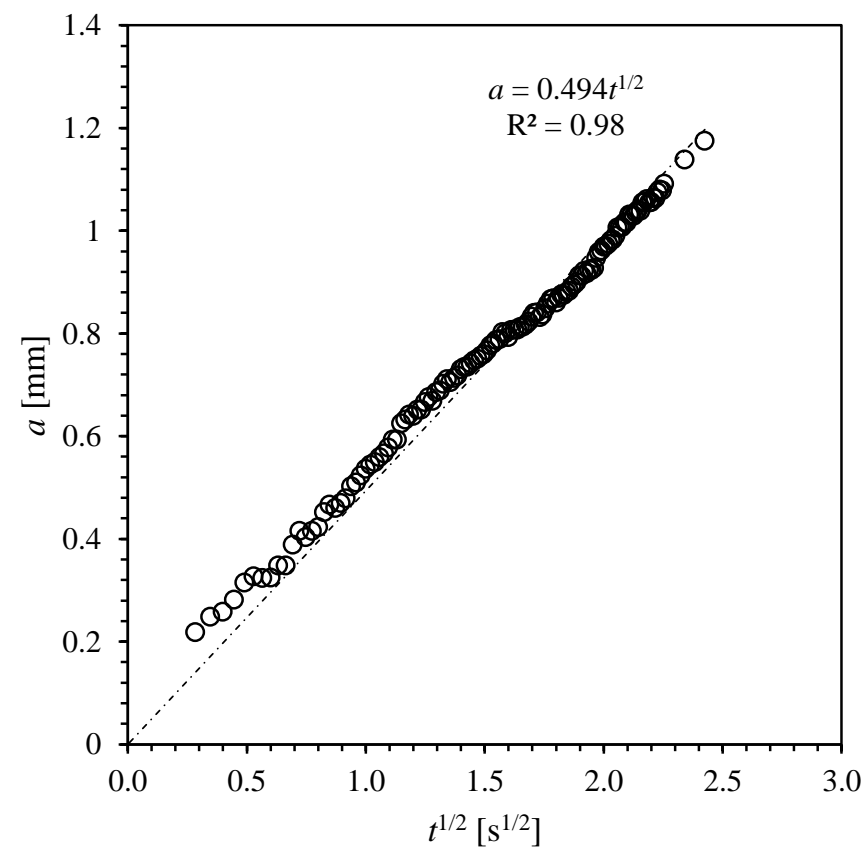

Figure S2 - Evolution of cleaning front for $d_{\mathrm{N}}=0.35 \mathrm{~mm}, U_{\mathrm{o}}=11.3 \mathrm{~m} \mathrm{~s}^{-1}$ 


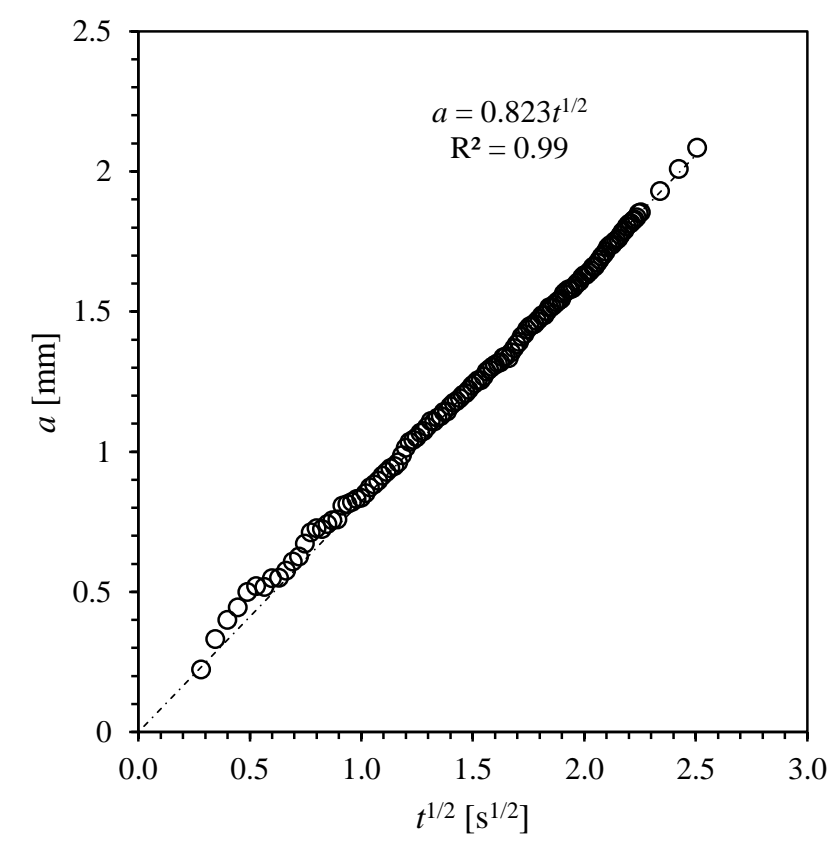

Figure S3 - Evolution of cleaning front for $d_{\mathrm{N}}=0.35 \mathrm{~mm}, U_{\mathrm{o}}=28 \mathrm{~m} \mathrm{~s}^{-1}$

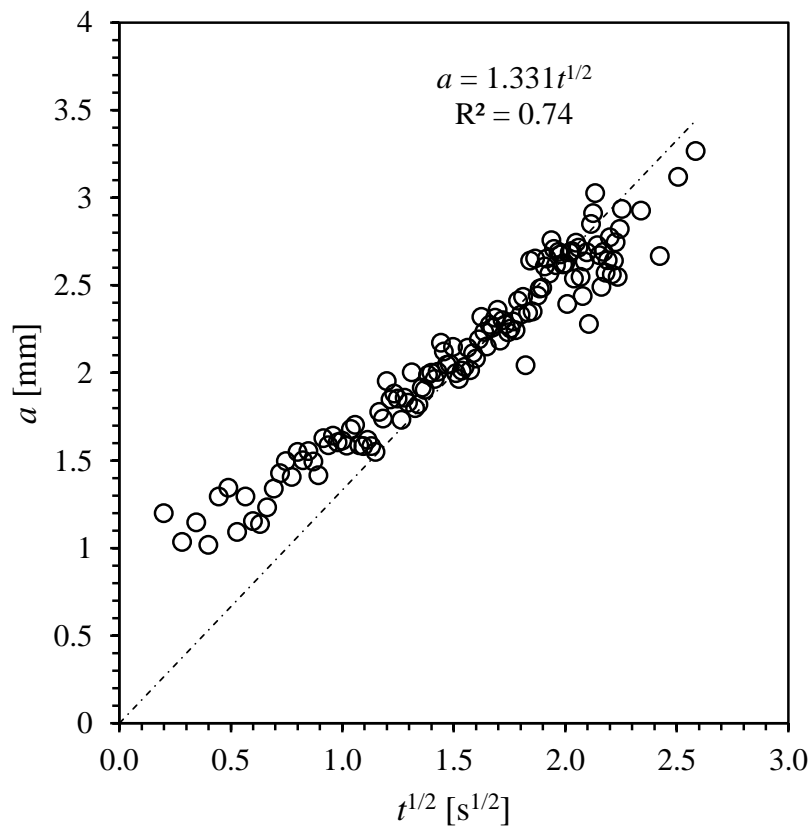

Figure S4 - Evolution of cleaning front for $d_{\mathrm{N}}=1.0 \mathrm{~mm}, U_{\mathrm{o}}=6.0 \mathrm{~m} \mathrm{~s}^{-1}$ 


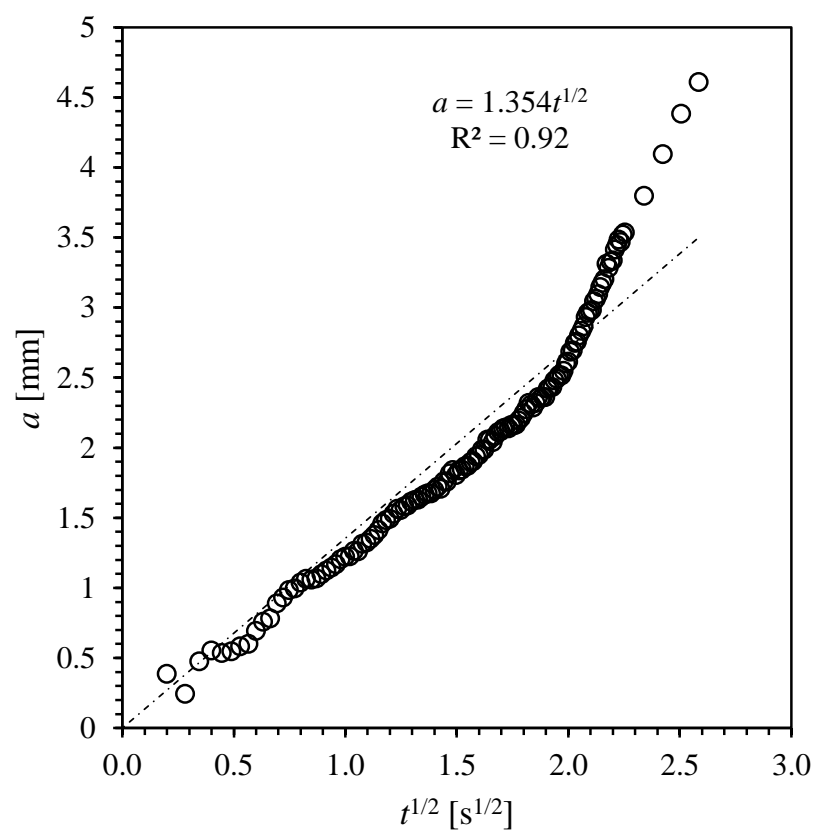

580

Figure S5 - Evolution of cleaning front for $d_{\mathrm{N}}=1.0 \mathrm{~mm}, U_{\mathrm{o}}=19.9 \mathrm{~m} \mathrm{~s}^{-1}$

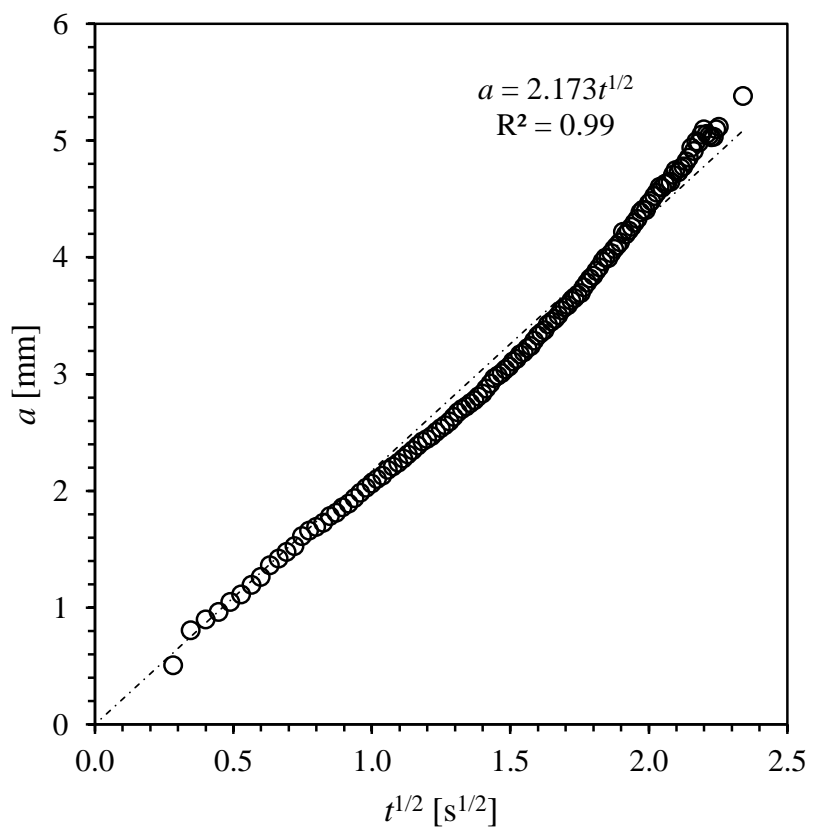

Figure S6 - Evolution of cleaning front for $d_{\mathrm{N}}=1.0 \mathrm{~mm}, U_{\mathrm{o}}=30.5 \mathrm{~m} \mathrm{~s}^{-1}$ 


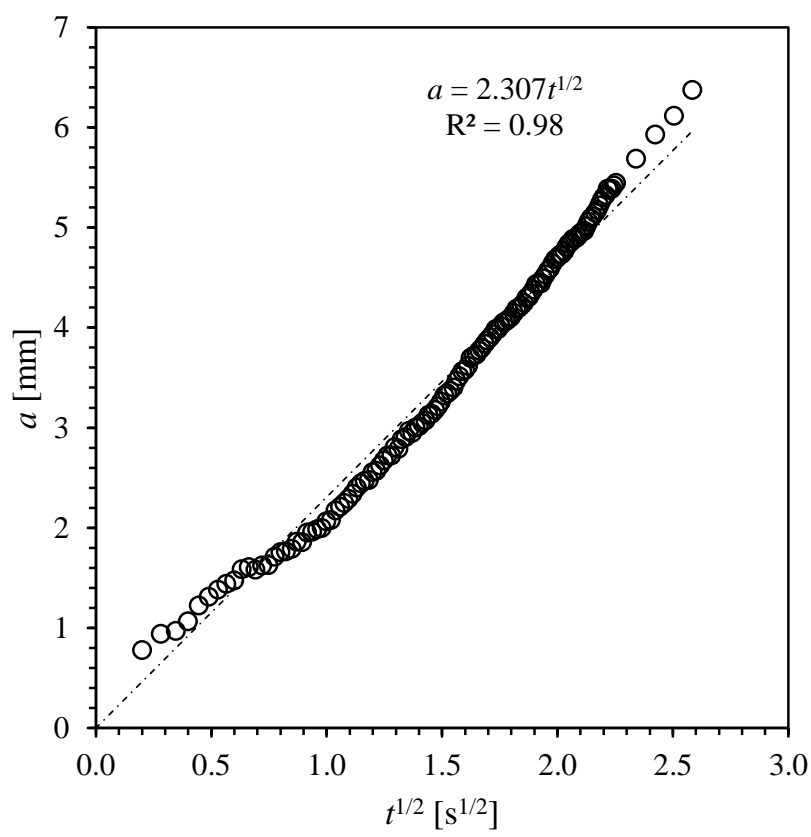

Figure S7 - Evaluation of cleaning front for $d_{\mathrm{N}}=1.5 \mathrm{~mm}, U_{\mathrm{o}}=13.5 \mathrm{~m} \mathrm{~s}^{-1}$

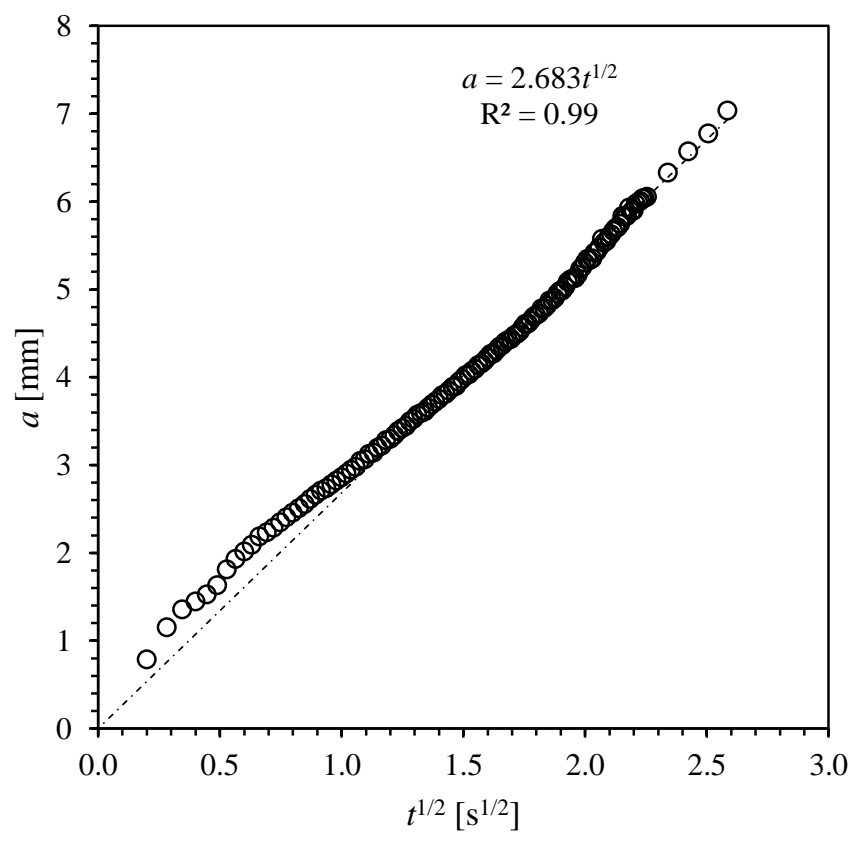

Figure S8 - Evolution of cleaning front for $d_{\mathrm{N}}=1.5 \mathrm{~mm}, U_{\mathrm{o}}=28 \mathrm{~m} \mathrm{~s}^{-1}$ 


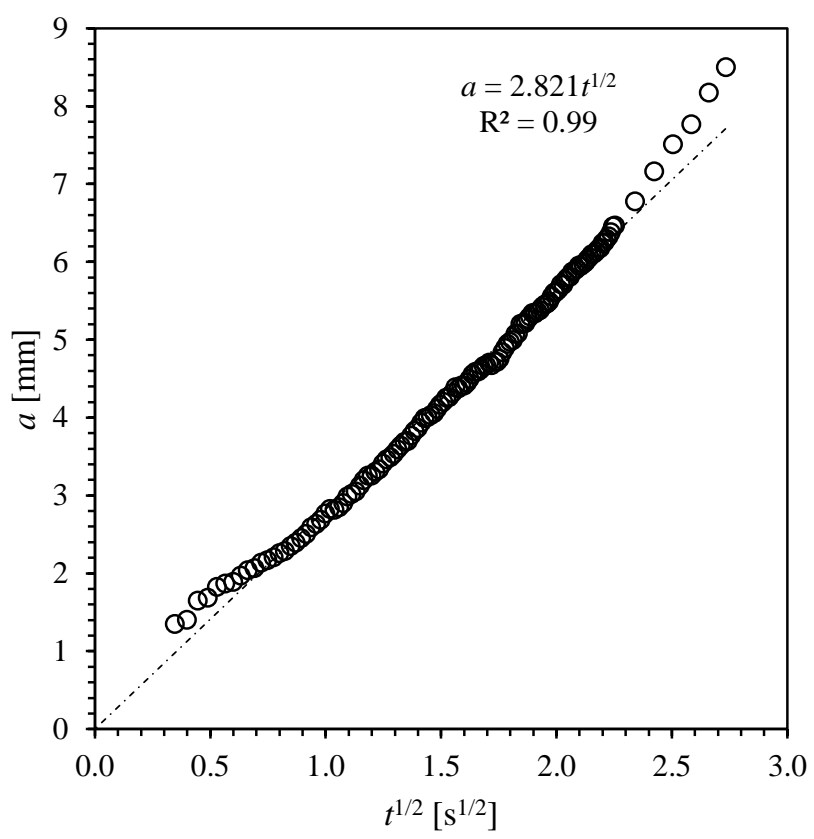

Figure S9 - Evolution of cleaning front for $d_{\mathrm{N}}=2.0 \mathrm{~mm}, U_{\mathrm{o}}=19.5 \mathrm{~m} \mathrm{~s}^{-1}$

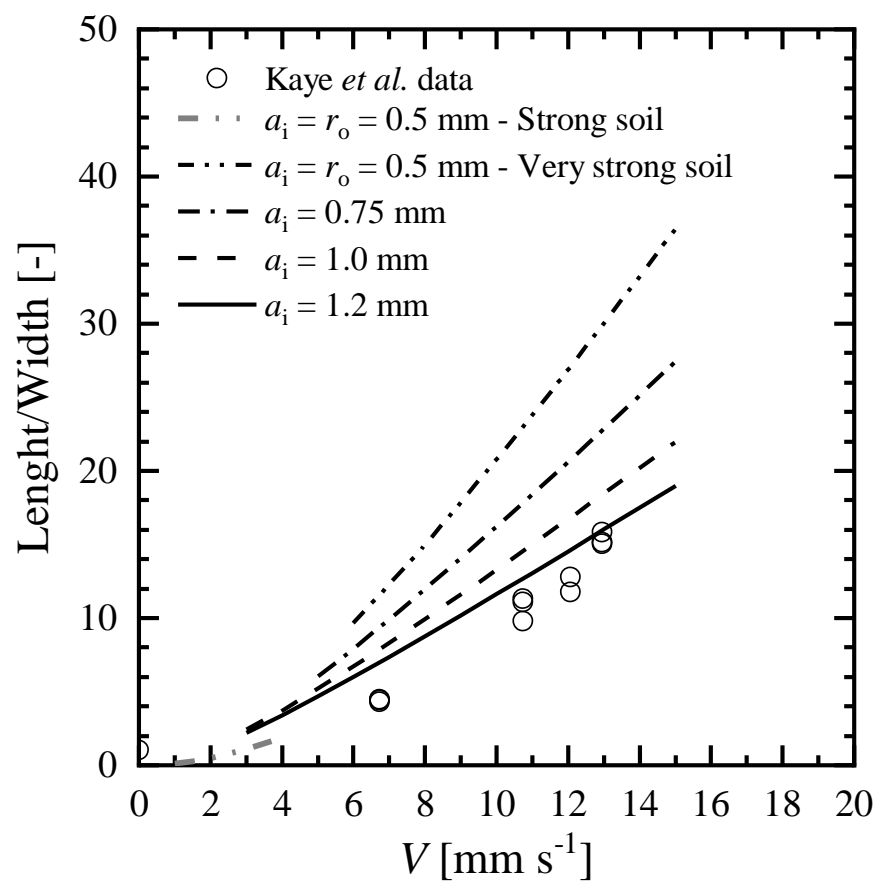

Figure S10. Aspect ratio of strip cleared by the moving nozzle (Figure 9); data extracted from Kaye (1995). Loci show model predictions for the case where $a_{\mathrm{x}}>r_{\mathrm{o}}$ (grey lines) and $a_{\mathrm{x}}<r_{\mathrm{o}}$ (black lines) 


\section{Supplementary Tables}

Table S1. Data plotted in Fig. 4

\begin{tabular}{ccccc}
\hline$r_{\mathrm{o}}[\mathrm{mm}]$ & $U_{\mathrm{o}}[\mathrm{m} / \mathrm{s}]$ & $r_{\mathrm{o}} U_{\mathrm{o}}\left[\mathrm{m}^{2} \mathrm{~s}^{-1} \times 10^{-3}\right]$ & $\sigma^{1 / 2}\left[\mathrm{~mm} \mathrm{~s}^{-1}\right]$ & Error bar $\left[\mathrm{mm} \mathrm{s}^{-1}\right]$ \\
\hline 0.125 & 19.9 & 2.49 & 0.55 & 0.06 \\
0.50 & 6.0 & 3.00 & 0.93 & 0.40 \\
0.175 & 28.0 & 4.90 & 0.82 & 0.04 \\
0.75 & 13.5 & 10.13 & 2.31 & 0.13 \\
0.50 & 30.5 & 15.25 & 2.17 & 0.16 \\
1.00 & 19.5 & 19.50 & 2.82 & 0.03 \\
0.175 & 11.3 & 1.98 & 0.49 & 0.05 \\
0.75 & 28.0 & 21.00 & 2.68 & 0.22 \\
0.50 & 19.9 & 9.95 & 1.24 & 0.04 \\
\hline
\end{tabular}

605 